\section{Ribeirinhos de Belo Monte}

"Aquele chão ainda estava a começar, recém-recente. As sementes ali se davam bem, o verde se espraiando em sumarentas paisagens. A vida se atrelava no tempo, as árvores escalando alturas. Um dia, porém, ali desembarcou a guerra, capaz de todas as variedades de morte. Em diante, tudo mudou e a vida se tornou demasiado mortal. Vieram da Nação apressados funcionários. Os delegados da capital sempre cumprem pressas quando estão longe de sua origem. E avisaram que os viventes tinham que sair, convertidos de habitantes em deslocados". A descrição do escritor sul-africano Mia Couto, em um dos contos do livro Histórias abensonhadas (Cia das Letras, 2012), ajuda a contar parte da história dos ribeirinhos de Belo Monte. Em um processo que se arrasta desde 2001, quando começaram a ser implantados os primeiros canteiros de obras e acampamentos de trabalhadores para a construção da barragem da Usina Hidrelétrica de Belo Monte, os ribeirinhos se tornaram deslocados.

O termo ribeirinho comporta uma definição ampla. No Xingu, eles são denominados beiradeiros, que vivem no beiradão. De acordo com Sônia Barbosa Magalhães, cientista

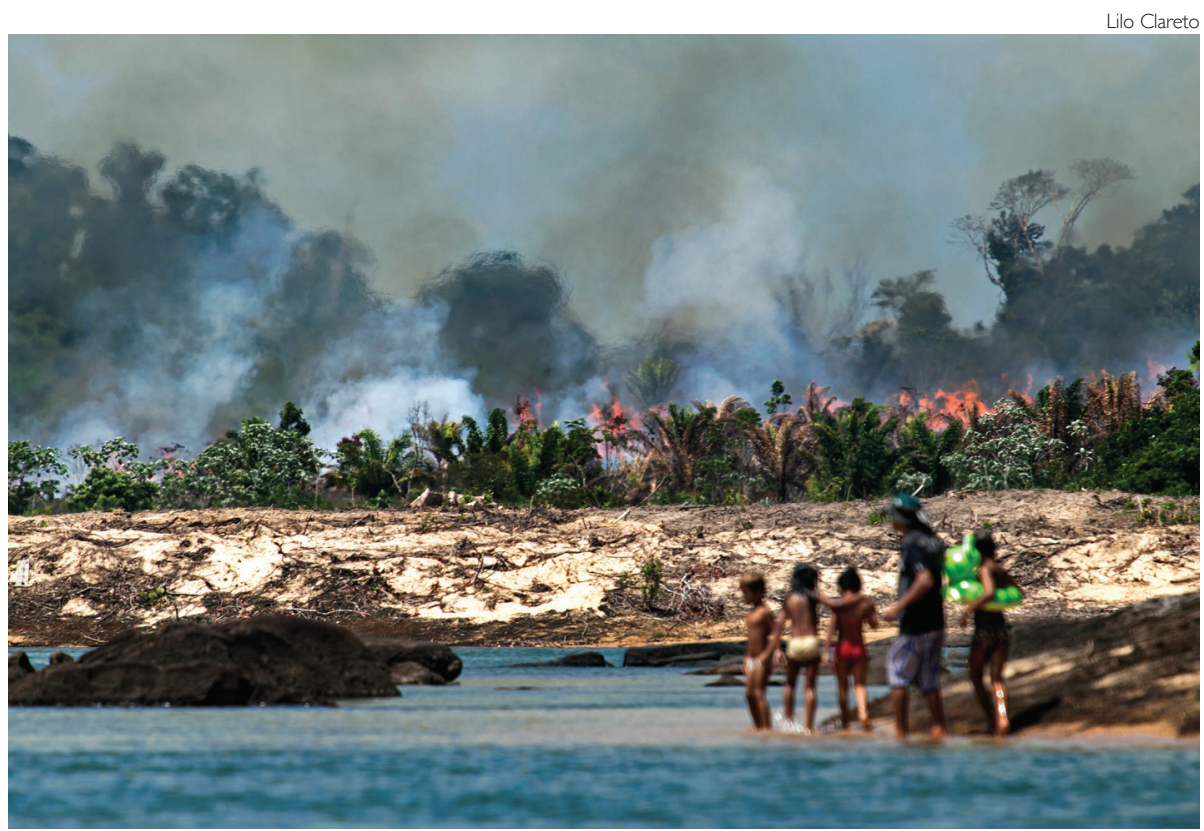

A Usina de Belo Monte gerou fortes impactos na vida da população ribeirinha

social e professora da Universidade Federal do Pará (UFPA), as características desse grupo resultam da relação que mantêm com a natureza, especialmente com o rio, combinando múltiplas atividades que se destinam à subsistência e ao mercado e que guardam forte relação com os períodos de cheias e de secas e com os recursos naturais disponíveis. A pesquisadora é uma das coordenadoras de um relatório sobre a situação das famílias de pescadores e lavradores que foram deslocados do seu ambiente, publicado pela Sociedade Brasileira para o Progresso da Ciência (SBPC) em 2017 e intitulado: $A$ expulsão de ribeirinhos em Belo Monte.
O rio Xingu tem seis meses de cheia, com grande parte das ilhas submersas (a intensidade das cheias varia ao longo dos anos), e seis meses do ano de secas com ilhas e praias expostas. No mesmo relatório da SBPC, as pesquisadoras Ana De Francesco, da Universidade Estadual de Campinas (Unicamp), Alexandra Freitas, Clara Baitello e Denise da Silva Graça, do Instituto Socioambiental (ISA), explicam: "Os ribeirinhos que habitavam a região do médio Xingu, onde hoje se encontra o reservatório da Hidrelétrica de Belo Monte, desenvolveram saberes e práticas ao longo dos anos, em um processo de experimentação e interação com o ambiente, transmitidas 
e enriquecidas ao longo de geraçóes no dia a dia do beiradão. Esses saberes estão presentes nas construções das casas, nos cultivos das roças, nos quintais agroflorestais, nas áreas de pesca e nas estratégias adotadas para responder à dinâmica das variações sazonais do rio Xingu”.

\section{BILOCALIDADE E DESLOCAMENTO DUPLO}

Outra característica do modo de vida desse grupo é adotar um fluxo de vida que reveza a permanência no beiradão e na cidade, em casas localizadas perto do rio já que o principal meio de transporte é o barco. Conforme explicam as pesquisadoras da Unicamp e do ISA, além de ser um ponto de apoio para a comercialização de produtos da pesca, da roça e do extrativismo, a casa na cidade era um meio de acessar educação para os filhos e os serviços públicos de saúde. Entretanto, a dupla moradia não foi reconhecida pela Norte Energia, consórcio de empresas responsável pela construção da hidrelétrica, forçando os ribeirinhos a se identificarem, na ocasião do cadastro socioeconômico, como sendo urbanos ou rurais. "Para a Norte Energia, a empresa concessionária de Belo Monte, e para o governo federal, os ribeirinhos sequer existiam. Ainda mais perverso do que expulsá-los da beira do Xingu era negar aquilo que são, torná-los um 'não ser'. E essa perversão foi cometida com eles", afirmou para a Ciência \& Cultura a jornalista e documentarista Eliane Brum, que desde 2011 faz reportagens sobre os impactos da construção da barragem na vida dos ribeirinhos.

Não é possível, entretanto, atribuir esse posicionamento da Norte Energia a algum tipo de desconhecimento sobre as características do modo de vida ribeirinho. "A Norte Energia tem larga experiência de construção de barragens na região. Isto porque a Norte Energia é um consórcio de empresas do qual 49,98\% são formados pela Eletrobrás e suas subsidiárias (Eletronorte e Chesf). A Eletronorte lidera a composição do consórcio com 19,98\%. A empresa iniciou a construção de hidrelétricas em 1974, com a hidrelétrica de Tucuruí também no estado do Pará. Logo, no setor elétrico, é quem mais conhece a região e suas especificidades", afirmou Magalhães.

$\mathrm{Na}$ cidade, o deslocamento levou famílias para bairros longe do rio, inviabilizando a manutenção das embarcações e gerando um custo de transporte para a realização da atividade pesqueira que não havia antes. A área dos baixões de Altamira foi transformada em um parque municipal, desfigurando a estrutura da localidade. O deslocamento rural atingiu todos os moradores do trecho do Xingu onde foi construído o reservatório da hidrelétrica e o deslocamento urbano atingiu 56\% das famílias. Por falta de acesso ao território e aos seus recursos naturais muitos tiveram que abandonar atividades extrativistas e a pesca.

De acordo com os pesquisadores da Pontifícia Universidade Católica do Paraná (PUC-PR), Liana da Silva, Bruna Gonçalves e Carlos de Souza Filho, no Brasil, as construçôes de barragens para a geração de energia elétrica, iniciadas de forma mais intensa na década de 1970, hoje estão voltadas para a região da Amazônia. A implantação dessas barragens tem ocasionando graves violações dos direitos humanos, em um padrão nacional recorrente. No caso de Belo Monte, houve a violação dos direitos humanos pelo deslocamento compulsório do grupo, pelo esfacelamento do seu modo de vida e de sua integralidade física e cultural. Para além desses fatores há os danos ambientais, "já que a construção da hidrelétrica devastou o ambiente natural, submergindo ilhas, tornando a água imprópria para o consumo em muitos locais, apodrecendo e extinguindo espécies de peixes que eram relevantes para o modo de vida de subsistência do ribeirinho", afirmam.

VELHOS OLHARES Para Brum esse olhar sobre os povos indígenas e a Amazônia ainda é, para grandes porções do Brasil, o mesmo da ditadura civil-militar. "É ainda o olhar do colonizador, que vê a floresta como um corpo para exploração e espoliação. E olha os povos da floresta como aqueles que não têm nenhum 


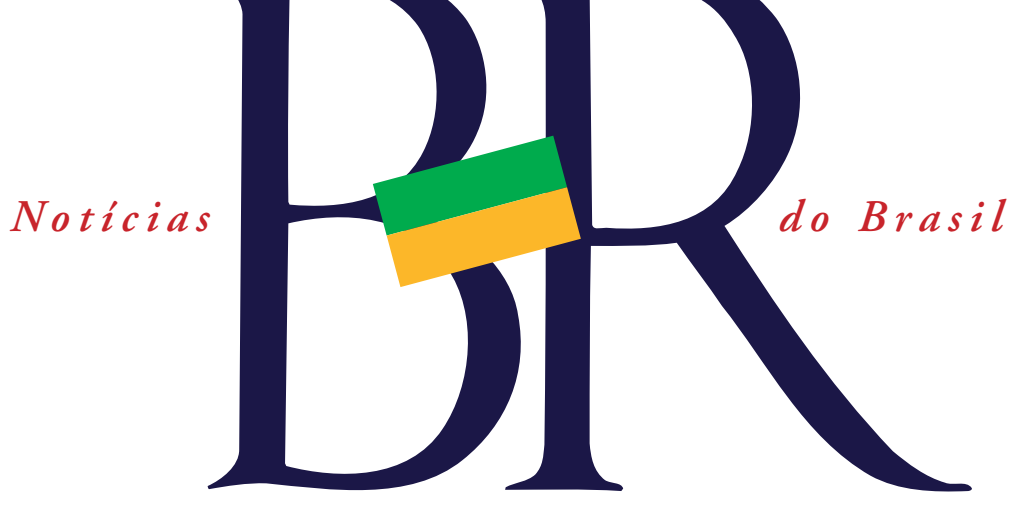

conhecimento a compartilhar e, portanto, nem mesmo o direito de determinar seu próprio destino", afirma. "É evidente que este olhar tampouco é inocente, já que ele sustenta um tipo de 'desenvolvimento predatório'. Trata-se, portanto, de desmatar para explorar, transformando a floresta em pasto para boi, plantação de soja, extração de minério ou hidrelétrica”, complementa. Ainda na opinião da jornalista, os ribeirinhos ou beiradeiros expulsos por Belo Monte foram submetidos também à outra concepção muito difundida: a conversão de povos tradicionais em pobres urbanos. As narrativas coletadas por Ana De Francesco e colaboradoras confirmam esse fenômeno. Um grande número de famílias vive uma situação de precariedade em relação à alimentação, saúde, geração de renda e qualidade de vida. Foi o que contaram os ribeirinhos Manoel Antônio Dias de Almeida e Isabel: "hoje tem que comprar tudo. Lá na ilha tinha peixe, carne, frutas, arroz, feijāo, farinha, tapioca. Hoje tudo mudou. Antes eu dizia, menino passa a bacia com essa goma para fazer uma tapioca para merendar. Hoje eu digo, menino pega o dinheiro para ir lá no mercado comprar alguma coisa para comer". Ainda de acordo com essas pesquisadoras, as famílias estão convivendo com problemas de violência urbana e insegurança: casas e barcos são roubados, roças saqueadas, a caça tornou-se uma atividade predatória e descontrolada. "O que ocorreu foi a ruptura dos mecanismos tradicionais de controle territorial ... assim, áreas que antes eram protegidas pelos ribeirinhos, que zelavam pelos recursos que ali existiam, hoje estão vulneráveis a um uso abusivo e predatório", afirmam.

RESISTÊNCIA A despeito da violência com que o deslocamento das pessoas desse grupo foi conduzido, há processos de resistência. "A resistência é diuturna e muitas vezes silenciosa. Está nas idas e vindas sem resposta ao escritório da Norte Energia; nas denúncias constantes ao Ministério Público Federal, à Defensoria Pública da União e do estado do Pará; na participação em reuniões com os movimentos sociais, como o Movimento Xingu Vivo e outros", afirmou Magalhães. A expressão mais concreta da luta pela reterritorialização dos povos ribeirinhos, condição para recompor seu modo de vida e para reparação dos danos ambientais causados pela barragem e seu reservatório, é o Conselho Ribeirinho. Reconhecido pelo Instituto Brasileiro do Meio Ambiente edos Recursos Naturais Renováveis (Ibama), o conselho foi constituído com apoio da SBPC, do Ministério Público Federal, da Defensoria Pública da União e de organizaçôes como o Instituto Socioambiental e o Movimento Xingu Vivo Para Sempre. "O Conselho Ribeirinho foi um enorme ato de resistência, uma afirmação de existência. E, junto com essa afirmação, a possibilidade de determinar seu destino. Até então era uma empresa privada que dizia quem era ribeirinho e quem não era ribeirinho, o que é totalmente perverso. A partir da constituição do Conselho Ribeirinho, os ribeirinhos dizem quem são. E, a partir desse reconhecimento, os beiradeiros têm lutado pelo reassentamento, mas não qualquer reassentamento. Têm lutado pela criação de um território ribeirinho no Xingu", afirmou Brum. A jornalista defende a necessidade do apoio de amplos setores da sociedade brasileira. "Não por concessão ou por bondade, mas porque a sociedade brasileira tem uma dívida com essas populações que, junto com os povos indígenas, são as que mantêm a floresta em pé", diz.

"No meu modo de ver, permanecer na beira do rio sob as condições mais adversas, sem casa, sem lugar é uma forma por excelência de resistir. $\mathrm{E} o$ livro publicado pela SBPC é uma manifestação concreta dessa resistência, é resultado da permanência deles para resgatar o que restou do seu território", disse a pesquisadora da UPFA, que concluiu afirmando que "negar a existência de povos indígenas e povos tradicionais não é resultado e nem pode ser atribuído a um imaginário distorcido. É uma questão do Estado, do reconhecimento de direitos e diz respeito a toda sociedade, a todos nós".

Patrícia Mariuzzo 